ISSN: 0210-7287

DOI: https://doi.org/10.14201/16162020105970

\title{
RETRATO DE POETA: VIDA Y LITERATURA DE JAIME GIL DE BIEDMA EN EL CÓNSUL DE SODOMA
}

\author{
Portrait of a Poet: Life and Literature of Jaime Gil \\ de Biedma in El cónsul de Sodoma
}

Javier SÁNCHEZ ZAPATERO

Universidad de Salamanca

zapa@usal.es

Recibido: diciembre de 2019; Aceptado: febrero de 2020; Publicado: diciembre de 2020

Ref. Bibl. JAVIER SÁNCHEZ ZAPATERO. RETRATO DE POETA: VIDA Y

LITERATURA DE JAIME GIL DE BIEDMA EN EL CÓNSUL DE SODOMA. 1616:

Anuario de Literatura Comparada, 10 (2020), 59-70

RESUMEN: El artículo analiza El cónsul de Sodoma, biopic del poeta Jaime Gil de Biedma. Para ello, y con el propósito de mostrar la estrecha relación que la película tiene con la literatura, se estudia su dimensión intertextual, manifestada a través de varios procedimientos temáticos, argumentales, estilísticos, expresivos y de citación. Asimismo, el artículo también se ocupa de otras cuestiones del filme como su adscripción al género del biopic literario, su correspondencia con la realidad histórica o su reflejo del ambiente literario e intelectual de Barcelona durante la segunda mitad del siglo xx.

Palabras clave: Cine; Poesía; Biopic; Jaime Gil de Biedma; El cónsul de Sodoma; Intertextualidad.

ABSTRACT: The article analyzes El cónsul de Sodoma, poet Jaime Gil de Biedma's biopic. For this, and with the purpose of showing the relationship 
that the film has with literature, its intertextual dimension is studied, manifested through various thematic, argumentative, stylistic, expressive and citation procedures. Likewise, the article also deals with other issues of the film such as its ascription to the genre of the literary biopic, its correspondence with the historical reality or its reflection of the literary and intellectual environment of Barcelona during the second half of the twentieth century.

Keywords: Cinema, Poetry, Biopic, Jaime Gil de Biedma, El cónsul de Sodoma, Intertextuality.

Sostiene Ángel Quintana que una película puede ser considerada como «un espacio formado por una serie de claves que ponen en evidencia la existencia de discursos anteriores, entendidos como los diferentes intertextos que hacen visibles los influjos culturales a los que se encuentra sometida" (2003, 44). Pese a que en su desarrollo se ha ido nutriendo de otras manifestaciones artísticas como la pintura -especialmente importante en el diseño de la puesta en escena o en el tratamiento de la luz y el color- o el propio cine -hay numerosos títulos que remiten a la tradición en la que se inscriben, como ponen de manifiesto, por ejemplo, los remakes-, el caso de intertextualidad fílmica más productivo e importante es el literario. Tal y como ha explicado Pérez Bowie, la presencia de la literatura en el cine puede producirse a través de varios procedimientos, entre los que, grosso modo, pueden citarse los trasvases argumentales; la conversión del mundo de la literatura en núcleo argumental y temático; la presencia de guiños, referencias y homenajes a textos o autores concretos; la recuperación y reescritura de mitos literarios; y la influencia de recursos expresivos (2008, 153-155).

El cónsul de Sodoma (Sigfrid Monleón, 2009) emplea algunos de estos mecanismos, demostrando con ello de forma paradigmática la variedad de modos a través de los que la literatura puede aparecer en la gran pantalla. Además de sustentar su estructura argumental en las últimas cuatro décadas de vida del poeta Jaime Gil de Biedma y adscribirse, por tanto, a la tradición genérica del biopic -analizada con detalle por Hueso (2009), Labé (2011), Moral (2006) o Pérez Bowie (2015)-, y en concreto a la del biopic de escritores, la película presenta un heterogéneo crisol de operaciones intertextuales que, oscilantes en un amplio espectro que va desde lo formal hasta lo temático, remiten a la tradición y la enunciación literarias. 


\section{PROCESO ADAPTATIVO}

Entre esos procedimientos, el más evidente es el que supone la relación de la película con la biografía de Miguel Dalmau Jaime Gil de Biedma (2004), cuya tercera parte -titulada, citando uno de los más representativos poemas del autor, "Contra Jaime Gil de Biedma»- fue utilizada como base del guion, en una adaptación caracterizada por la fidelidad. De ese modo, partiendo de algunos de los más significativos episodios de su recorrido vital -entre los que destacan su trabajo en la Compañía de Tabacos de Filipinas, sus recurrentes estancias profesionales en el país asiático, la tirantez del trato con su familia, el apasionamiento autodestructivo de sus relaciones sentimentales, su compromiso político, sus presencia en ambientes intelectuales de Barcelona y, por supuesto, sus procesos de creación literaria-, la película intenta ofrecer un retrato de la singular y contradictoria personalidad de quien fue, al mismo tiempo, «ejecutivo en una empresa, escritor al que gustaba más leer que escribir, homosexual que se enamoró de una mujer, hijo de familia acomodada e ilustre al que le gustaba introducirse en la lujuria sexual de barrio bajo [y] amante de la vida» (Ocaña 2010). Esta complejidad es reflejada en el propio esquema argumental, que reproduce la narración causal típica de los relatos vitales, ordenando los acontecimientos en función de su contribución al retrato biográfico global. Así se observa, por ejemplo, en los planos iniciales del filme, que muestran, a través de los cambios de escenario y de la variedad cromática del vestuario, cómo el protagonista combina su periplo por antros en los que recurre a la prostitución con reuniones de negocios de alto nivel en elegantes salones, generando una dualidad que no hace sino dotarse de un sentido teleológico por el que se trata de definir su contradictoria personalidad. El juego de contrastes es recurrente a lo largo de toda la película y se manifiesta de múltiples formas, como ejemplifica la oposición entre el tono soez de las conversaciones de Gil de Biedma con sus amantes y el dandismo de su apariencia pública o entre el bullicio de los escenarios urbanos de Manila y Barcelona y la tranquilidad que transmiten los ambientes rurales de Nava de la Asunción, el pueblo segoviano del que era oriunda su familia, o de Ultramort, la localidad ampurdanesa a la que se trasladó a vivir a principios de la década de 1970.

De las posible tramas que podrían surgir a partir de esa poliédrica estampa, el filme se centra en la que "concierne a su aprendizaje sentimental y sexual, en detrimento de, por ejemplo, su desarrollo poético, la conciencia política o historias de amistad, aspectos que aparecen tratados pero consignados a los márgenes» (Mira 2011, 120). Abordar la sexualidad implica indagar en algunos de los pasajes más escabrosos de la vida del poeta: promiscuidad, participación en orgías, uso de servicios de prostitución, etc. 
La inclusión de esos episodios en la película, representados de forma explícita en casi todos los casos, ha de ser relacionada con la tendencia de la industria cinematográfica de elegir como protagonistas de biopic literarios, además de a los más relevantes y reconocidos autores del canon, a escritores que tuvieran una vida iconoclasta, como ponen de manifiesto, sin ánimo de exhaustividad, casos como los de Henry Miller, Yukio Mishima, Allen Ginsberg, Joe Gould o Charles Bukowski. De hecho, para Mañas Martínez, «es ingenuo pensar que la película se hubiera realizado si Jaime Gil de Biedma hubiera tenido una vida ortodoxamente ajustada a las normas sociales de su época, y no hubiera habido ninguna heterodoxia en la que escarbar» (2010). El escándalo que ciertos comportamientos del autor provocaron -que, tal y como se muestra en el filme, llegaron a provocar que se le chantajeara amenazándole con difundir unas fotografías de su vida íntima-, así como la singular condición de su personalidad, comprometida hasta el punto de querer ingresar de forma clandestina en el Partido Comunista y rupturista por tratar de vivir con libertad su homosexualidad en la pacata sociedad del tardofranquismo, son, de hecho, dos de los elementos fundamentales de la película, que se distingue de ese modo de buena parte de biografías fílmicas nacionales. La escasa tradición del biopic en la cinematografía española, de la que ya nos ocupamos en un trabajo precedente (Sánchez Zapatero 2019), ha provocado que, hasta la fecha, los escritores cuya vida ha sido llevada a la gran pantalla hayan sido, habitualmente, representantes del canon-como evidencian los casos de Lope de Vega, Miguel de Cervantes, Teresa de Jesús o Juan de la Cruz- o, siguiendo con el recurrente tratamiento de la Guerra Civil y la dictadura, figuras literarias relacionadas de algún modo con ese periodo histórico como Miguel Hernández, Federico García Lorca o María Zambrano.

La deuda de El cónsul de Sodoma con el texto biográfico no se limita a lo argumental y lo temático, sino que alcanza también al modo de reconstruir la historia del protagonista. Al tomar la obra de Dalmau como hipotexto principal -por encima incluso de algunos de los textos autobiográficos que el propio Gil de Biedma escribió, como Diario del artista seriamente enfermo (1974) o Retrato del artista en 1956 (1991), empleados solo de forma tangencial y complementaria-, la película termina por asumir un discurso que, en ocasiones, se basa en la conjetura más que en el cotejo de documentos o testimonios, otorgando así la categoría referencial -O al menos pretendidamente referencial, en la medida que en su recepción también participa la experiencia estética propia del cine convencional de ficción al que se ajusta su estructura discursiva- de la que el biopic dota a la narración de hechos cuya veracidad no está probada por su pertenencia a la esfera de la intimidad. 
Así sucede, por ejemplo, con la secuencia en la que se relata la estancia del escritor estadounidense James Baldwin en España en mayo de 1962. Gil de Biedma le conoció gracias a la intermediación de Carlos Barral y le dedicó, de hecho, su poema "En una despedida». Adscrito, como toda su obra, a la poesía de la experiencia, y susceptible de ser leído, por tanto, como si "su vida privada se hubiera consumado en ella» (Ferraté 1980, 300), la composición define los días que pasaron juntos en Barcelona como una "extraña semana»: "A solas con tu imagen / cada cual se conoce por este sentimiento / de cansancio, que es dulce -como un brillo de lágrimas / que empaña la memoria de estos días / de esta extraña semana» (Gil de Biedma 2000, 100). En los documentos personales Gil de Biedma que se publicaron de forma póstuma en 2015 bajo el título de Diarios 1956-1985 -a los que, por lógicos motivos relacionadas con la fecha de publicación, no pudieron acceder ni Dalmau ni León para preparar sus respectivas biografía y película- también aparece una referencia a su encuentro con Baldwin, resumido en parecidos términos a los empleados en el poema. En la entrada del 14 de mayo de 1962, escribe el autor que su vida, desde que conoció al escritor estadounidense, "ha sido tan agitada» que se encuentra "en un estado de verdadero agotamiento moral y físico, agravado por la torpeza intelectual que trae consigo un régimen alcohólico como el que h[a] venido siguiendo» (2015, 134). Ahora bien, este encuentro, documentado y del que dan fe también algunos de quienes formaban el círculo de amistades del autor en la época, como el propio Barral o Juan Marsé, se complementa en la película con un acto sexual mostrada de forma sugerente, a través de un plano en el que se ve a los dos escritores despertándose desnudos en la misma cama. Obviamente, teniendo en cuenta el proceso adaptativo del que nace el filme, no hay dudas de que la presencia de esa imagen se debe a su aparición en el hipotexto del que parte, pero sorprende comprobar cómo en la biografía de Dalmau la relación simplemente se presupone, sin llegar jamás a corroborarla, ni a aportar prueba alguna de que sucediera más allá del testimonio de una de las parejas de Gil de Biedma. Después de insinuar que Baldwin pudo sentirse atraído por el poeta - «es fácil imaginar la sorpresa del americano al toparse [...] con un señorito español, anglófilo, de gustos refinados e inclinaciones canallas»-, de aludir a unas declaraciones del editor Jaime Salinas en las que afirmaba que al autor estadounidense "los hombres blancos [...] le gustaban mucho" y de sostener de forma un tanto simplista que ambos tenían inquietudes afines como «el París de 1953, la poesía negra de los veinte, el calor de otros hombres», el biógrafo señala que es posible "conjeturar [...] qué ocurrió exactamente durante la semana" y se aventura a afirmar que "probablemente hubo flirteos, equívocos, seducciones, [...], sexo, intensidad, vida» (Dalmau 2004, 297-298). 
Pese a que en la biografía, cuyos resultados han llegado a ser calificados "más bien chismológicos que filológicos» (Mañas Martínez 2010), se especifica que lo que ocurrió entre Baldwin y Gil de Biedma "pudo, en efecto, ser así [...] o pudo ser algo absolutamente distinto e incluso un mezcla de todo" (Dalmau 2004, 298), El cónsul de Sodoma lo asume como cierto y lo incluye dentro de una película en la que, debido a su condición de biopic y de variante del cine histórico, "la veracidad constituye una de sus señas de identidad” (Pérez Bowie 2008, 142). De ese modo, se produce un contraste entre la conjetura de lo que pudo pasar y la evidencia de lo que pasó, representado por el protagonismo de un personaje real, cuyos detalles vitales más significativos pueden ser conocidos fácilmente por el gran público, y por la presencia de elementos complementarios de veredicción como la utilización paratextual de rótulos sobreimpresionados que anclan la historia a un espacio y a un tiempo concretos, la detallada ambientación del pasado reciente o la presencia de marcas históricas fácilmente reconocibles por el gran público: sin ánimo de exhaustividad, se alude a sucesos como la muerte de Franco o la incorporación de España a la Comunidad Económica Europea con imágenes procedentes de noticiarios televisivos que refuerzan su referencialidad, y hay numerosos personajes reales.

\section{AMBIENTES Y PERSONAJES LITERARIOS}

La utilización de seres históricos, recreados en muchos casos con gran fidelidad gracias a la caracterización de sus intérpretes, puede considerarse también como una marca de intertextualidad por la condición de escritores de muchos de ellos. Además del ya citado Baldwin, aparecen en la película Carlos Barral, Juan Marsé o Enrique Vila-Matas. Mientras que los dos primeros tienen gran relevancia en la trama, puesto que fueron grandes amigos de Gil de Biedma -y en el caso del primero, además, su editor-, el segundo aparece de forma tangencial, durante una única escena en la que se presenta como responsable de la sección "Oído en Boccaccio» de la revista Fotogramas. Su inclusión en la película, por tanto, está al servicio de la recreación del ambiente intelectual y bohemio de la Barcelona de la posguerra y, de forma concreta, de la conocida como gauche divine que se reunía en locales como, precisamente, Boccaccio y a la que, además de Gil de Biedma o Barral, pertenecían otros personajes que aparecen en la película como la fotógrafa Colita o Isabel Gil, Bel, con quien el poeta mantuvo una relación sentimental. 
Más allá de en su condición de iconos del panorama cultural nacional, la importancia de Barral y Marsé reside en que representan, debido a sus trayectorias y concepciones, dos modos muy diferentes de afrontar la creación literaria y de configurar su imagen pública como escritores. Su presencia, en consecuencia, contribuye a reforzar el poliedrismo del retrato de Gil de Biedma, que comparte con ambos escenas en las que se muestran, por un lado, la erudición y el compromiso político del editor y poeta, con quien mantiene conversaciones trufadas de referencias artísticas, reflexiones sobre la situación política y recomendaciones lectoras, y, por otro, la concepción de "escritor-obrero" que de sí mismo tenía el novelista, que expone su poética realista al afirmar que "se limit[a] a escribir lo que v[e]». No en vano, el propio Gil de Biedma llegó a asegurar que su amistad con Marsé procedía precisamente del hecho de que ambos procedían de «dos culturas muy distintas [...], pero las dos a extinguir", "dos sistemas de actitudes éticas [...] que ya no tienen nada que ver con la vida misma", lo que provocaba que su "relación con el mundo [fuera] muy parecida" $(2002,184)$. El orgullo obrero del novelista, que ansiaba poder vivir de la literatura y dejar su trabajo en una joyería, contrasta con los orígenes burgueses del poeta, para el que la literatura siempre fue, más que una actividad profesional, una manera estética de posicionarse ante el mundo y de definir su identidad. De ahí que llegase a abandonar la escritura poética -que no la literatura, ya que siguió publicando algunos textos ensayísticos y siendo un gran crítico y lector, pues, como confesó en la nota paratextual que acompañaba a Las personas del verbo (1975), "lo normal es leer»- y que desde la publicación en 1968 de Compañeros de viaje apenas ofreciese nuevas composiciones, convencido de que «el proyecto de construcción del poeta (como ficción que absorbe a su yo) estaba acabado, con lo que la poesía dejaba de tener el valor primigenio» (Sánchez García 2018, 32).

Esta disímil concepción de literatura se manifiesta especialmente en la secuencia que relata la estancia de los dos escritores en Nava de la Asunción, donde pasaron juntos una temporada. Las conversaciones sobre el modo que ambos tenían de afrontar el proceso creativo se complementan con las alusiones a la escritura de Últimas tardes con Teresa (1966), que Marsé estaba terminando por entonces. De hecho, en algunas escenas se ve al novelista redactando la obra y en otras aparece Gil de Biedma ofreciendo su opinión sobre ella. Para definir al personaje del "Pijoaparte», el poeta utiliza en un diálogo las palabras del poema "Joven charnego mítico": "Camisa rosa. Tejanos. / Actitud provocadora. / Y una sonrisa, que es / demasiado encantadora. / Murciano. / Olor a gato montés» (Cuenca 2014, 117), que se publicó con una dedicatoria al propio Marsé. 


\section{INTERTEXTOS POÉTICOS}

Lejos de ser excepcional, la utilización de los versos conecta con uno de los más fértiles procedimientos intertextuales empleados en la película, en la que llegan a aparecer otros doce poemas de Gil de Biedma. La mayoría de ellos son recitados a través de una voz en off heterodiegética que, sin embargo, se identifica en todos los casos excepto en uno con la del propio poeta. Su inclusión no tiene un valor meramente ornamental, como sucede en otros biopics, sino que, aprovechándose del componente confesional que casi todo ellos tienen, está al servicio de la configuración del protagonista y del relato de sus principales episodios vitales, sin que eso signifique siempre que se inserten dentro del momento histórico en el que fueron compuestos. Así, por ejemplo, su voluntad crítica y su compromiso político y social se manifiestan en "Apología y petición»: "Y qué decir de nuestra madre España, / este país de todos los demonios / en donde el mal gobierno, la pobreza / no son, sin más, pobreza y mal gobierno / sino un estado místico del hombre, / la absolución final de nuestra historia» (Gil de Biedma 1988, 82). El recitado de este poema, que contiene algunos de los versos más difundidos de su trayectoria - «De todas las historias de la Historia / sin duda la más triste es la de España / porque termina mal» (Gil de Biedma 1988, 82)- contrapuntea unas imágenes en las que se observa al autor desarrollando su rutina laboral en la Compañía de Tabaco y aprovechando las horas que pasa en su oficina para escribir. Los planos en los que se ve el proceso de composición poética son los únicos de toda la película en los que se expone cómo afrontaba la actividad escritural Gil de Biedma, a quien se presenta rellenando folios en su escritorio. Cumpliendo con uno de los más habituales tópicos de las películas biográficas sobre escritores, también hay algunos planos subjetivos que reproducen la mirada del autor sobre el papel en blanco en el que de forma progresiva se van manuscribiendo los versos.

También son declamados "Contra Gil de Biedma", sintomático ejemplo de la dualidad que escindía al poeta - «De qué sirve, quisiera yo saber, cambiar de piso, / dejar atrás un sótano más negro / que mi reputación -y ya es decir-, / poner visillos blancos / y tomar criada, / renunciar a la vida de bohemio, /si vienes luego tú, pelmazo, / embarazoso huésped, memo vestido con mis trajes, / zángano de colmena, inútil, cacaseno, / con tus manos lavadas, / a comer en mi plato y a ensuciar la casa?» (Gil de Biedma 1988, 1945)- y que, consecuentemente, es recitado mientras las imágenes denotan las diferentes aristas de su personalidad; y "Conversación", cuya temática fúnebre -«Los muertos pocas veces libertad / alcanzáis a tener, pero la noche / que regresáis es vuestra, / vuestra completamente» (Gil de 
Biedma 1988, 159)- intensifica el impacto de unas imágenes en las que se ve a Gil de Biedma, aturdido por la noticia de la muerte de Bel, intentando suicidarse. Asimismo, en la parte final de la película, mientras la caracterización del protagonista muestra visualmente el inexorable efecto del paso del tiempo, se incluyen tres de los poemas en los que abordó el tempus fugit: "De senectute», que acompaña las imágenes del acto por el que fue reconocido como cónsul honorario de Filipinas en Barcelona; «Himno a la juventud", que conecta con la melancolía que siente el poeta al ver bailar en la playa a uno de sus compañeros sentimentales, más joven que él; y "No volveré a ser joven", cuyos versos son recitados mientras se observan las terribles consecuencias de una violenta pelea en el ámbito doméstico que terminó con Gil de Biedma malherido y tendido a la intemperie sobre la nieve.

La única ocasión en la que los poemas son leídos por una voz en off que no se corresponde con la del protagonista tiene lugar en la secuencia en la que se narra la muerte de su padre. Las imágenes del duelo familiar son complementadas con los versos elegíacos de "Son pláticas de familia»-"Qué me agradeces, padre, acompañándome / con esta confianza / que entre los dos ha creado tu muerte? / No puedes darme nada. No puedo darte nada, / y por eso me entiendes» (Gil de Biedma 1988, 167)- puestos en boca del personaje de su madre.

Otras composiciones, en cambio, aparecen como sonidos homodiegéticos. Sucede, por ejemplo, con "Por lo visto», otro de los ejemplos de la poesía comprometida del autor, que un agente de policía lee de un pasquín en el contexto de un interrogatorio; "Pandémica y celeste", cuyos versos se van alternando en el juego de seducción que supone su primer diálogo con Bel; "A una dama muy joven, separada", recitado por un abogado de forma monótona, sin ritmo ni entonación, en el juicio por la custodia de los hijos de Bel como prueba de adulterio, utilizando para ello el carácter testimonial de la poesía de la experiencia; y «La vida a veces», declamada por el propio poeta en un acto público en una de las secuencias finales. En ocasiones, fragmentos de las composiciones son incluidos en diálogos, convirtiéndose en parte del discurso cotidiano de Gil de Biedma y ocultando, por tanto, su origen poético, como cuando, en el contexto de una conversación, utiliza para definirse dos versos de "Infancia y confesiones" - Yo nací (perdonadme) / en la edad de la pérgola y el tenis» (Gil de Biedma 1988, 49)- que evocan a Rafael Alberti.

Los intertextos que se incorporan a los parlamentos no proceden solo de la producción poética, sino que también hay algunos que remiten a pasajes ensayísticos y autobiográficos e incluso a fragmentos de entrevista. Las primeras palabras que el protagonista pronuncia en la película, de 
hecho - "prefiero ser poema» (Gil de Biedma, 1988)- son tomadas de la nota paratextual que acompañó la edición de Las personas del verbo, de donde también procede, parcialmente, la frase con la que en una de las escenas reacciona a la creación del término gauche divine por parte de Joan Segarra: mientras que en la película dice "de izquierdas ya no ejerzo, y de divino ni te cuento", en el texto original se puede leer "he sido de izquierdas y es muy probable que siga siéndolo, pero hace ya algún tiempo que no ejerzo" (Gil de Biedma, 1988). Asimismo, la denuncia de la injustica social de las palabras con las que el poeta, a través de la voz en off, acompaña su mirada sobre los suburbios de Manila - -Y eso, la miseria absoluta, el vivir continuamente hostigados por las necesidades, será su vida humana, será toda su vida" (Gil de Biedma 2015, 145)- procede de Retrato del artista en 1956. Y de una entrevista que le hizo la periodista Maruja Torres surge la descripción de Bel como "cisne desmesurado" (Gil de Biedma 2002, 129) que hace en la película.

Además, la obra y la concepción literarias de Gil de Biedma se manifiestan también a través de la presencia en pantalla de algunos de sus libros, habitualmente subrayados por el uso de planos detalle, así como por las opiniones que van salpicando algunas de sus conversaciones, que, entre otras cosas, le llevan a definir al grupo poético de los Novísimos como «jóvenes y fácilmente impresionables», a aconsejar a un autor novel que "Solo hay una manera de vivir la poesía a fondo, y es vivirla de joven", o a presentarse en los últimos años de su vida, cuando ya es un poeta venerado por las nuevas generaciones, como un «escritor lento» que solo ha escrito "tres poemarios más bien breves".

Pero las referencias literarias de El cónsul de Sodoma no alcanzan solo a la producción y la poética del autor protagonista, sino que también aluden a otros escritores y obras. No obstante, evidenciando el afán autobiográfico que persigue al filme, su presencia en la película está siempre al servicio del retrato de Gil de Biedma. De ahí que se le presente en diversos momentos leyendo Cuatro cuartetos (Four quartets, 1941), de T. S. Eliot, o Cónsules de Sodoma (2004), de Winston Layland. La primera obra, que aparece en la película en su versión original, fue una de las lecturas de referencia del autor, que no solo llegó a prologar una de sus traducciones al español, sino que siempre admitió su deuda con el poeta anglosajón, cuya influencia, según la crítica, constituye «una de las características más fácilmente identificables su de obra" (Walsh 2004, 6). La segunda, por su parte, se trata de una antología de entrevistas que Layland publicó en la revista estadounidense Gay Sunshine para cuya traducción al castellano en 1982 se empleó un título sugerido por el propio Gil de Biedma. Subrayando la importancia intertextual que le otorga el hecho de haber sido elegido 
como base del título de la propia película, en un diálogo el poeta usa la expresión, al ser preguntado sobre la opinión que le merece haber sido nombrado cónsul honorario de Filipinas, para manifestar que él en su vida solo se ha sentido "cónsul de Sodoma».

\section{CONCLUSIÓN}

A la vista de lo expuesto, no será necesario insistir en la obviedad que supone afirmar que El cónsul de Sodoma es una película de y sobre poesía. La relevancia que los procedimientos intertextuales adquieren en su composición y desarrollo, susceptibles de ser catalogados en el amplio espectro que han intentado sistematizar las páginas precedentes, pone de manifiesto de forma sintomática las muchas y muy variadas formas a través de las que la literatura puede hacerse presente en la pantalla. De ese modo, casos como el del biopic de Gil de Biedma demuestran que la tradicional mirada del comparatismo, especialmente centrada en los trasvases argumentales, y generadora, por tanto, de una interpretación reduccionista de las relaciones filmoliterarias, ha de ser progresivamente sustituida por una concepción de las películas, incluso de aquellas que surgen de procesos adaptativos, como entidades artísticas autónomas dotadas de una dimensión intertextual en las que la literatura cobra una especial relevancia y se manifiesta de forma tanto explícita como subyacente.

\section{REFERENCIAS BIBLIOGRÁFICAS}

Cuenca, Josep Maria. Mientras llega la felicidad. Una biografía de Juan Marsé. Barcelona: Anagrama.

Dalmau, Miguel. 2004. Jaime Gil de Biedma. Barcelona: Circe.

Ferraté, Juan. 1980. "A favor de Jaime Gil de Biedma». En Yndurán, Domingo (ed.). Época contemporánea 1939-1980 [RIco, Francisco (dir.). Historia y crítica de la literatura española], 294-300. Barcelona: Crítica.

GIL DE BIEDMA, Jaime. 1988. Las personas del verbo. Barcelona: Seix Barral.

Gil de Biedma, Jaime. 2000. Antología poética, ed. Javier Alfaya. Madrid: Alianza.

GIL DE BIEDmA, Jaime. 2002. Jaime Gil de Biedma. Conversaciones, ed. Javier Pérez Escohotado. Madrid: Austral.

GIL DE Biedma, Jaime. 2006. Retrato del artista en 1956. Barcelona: Península.

GIL DE BIEDma, Jaime. 2015. Diarios 1956-1985, ed. Andreu Jaume. Lumen: Barcelona. 
Hueso, Ángel Luis. 2009. "Reflexiones sobre la biografía cinematográfica». En PÉREz DE las Heras, Beatriz y Vanessa De la Cruz (eds.). Filmando la historia. Representaciones del pasado en el cine. Madrid: Ediciones JC, pp. 83-95.

LABÉ, Benjamin. 2011. "Vraisamble et vérité: La question du realisme et ses paradoxes». En Fontanel, Rémi (dir.). Biopic: de la realité à la fiction. París: CinemAction, pp. 42-47.

MaÑAS MARTínEZ, María del Mar. 2010. "El cónsul de Sodoma: ¿Contra Jaime Gil de Biedma?». Entre libros anda el cine. Sobre cine y literatura. Web.

MirA, Alberto. 2011. "Poetas en el cine: paradigmas teóricas en dos narrativas biográficas (Little Ashes y El cónsul de Sodoma)». Lectora: revista de dones i textualidad, 17, pp. 123-138.

Moral, Javier. 2006. "Biopic y veredicción». En Pérez Perucha, Julio y Pedro POYATOS (eds.). ¡Savia nutricia! El lugar del realismo en el cine español. Actas del XI Congreso Internacional de la Asociación Española de Historiadores del Cine. Córdoba: Filmoteca de Andalucía, pp. 127-133.

OCAÑA, Javier. 2010. "La contradicción del poeta». El País, 8 de enero. Web.

PÉREZ BowIE, José Antonio. 2008. Leer el cine. La teoría literaria en la teoría cinematográfica. Salamanca: Ediciones Universidad de Salamanca.

PÉREZ Bowie, José Antonio. 2015. «En torno a la biografía fílmica. Una propuesta de tipología». En Pérez BowIe, José Antonio y Pedro Javier PARdo (eds.). Transescrituras audiovisuales. Madrid: Pigmalion, pp. 19-45.

Quintana, Ángel. 2003. Fábulas de lo visible. El cine como creador de realidades. Barcelona: El Acantilado.

SÁnCHEZ García, Remedios. 2018. Así que pasen treinta años. Historia interna de la poesía española. Madrid: Akal.

SÁNCHEZ ZAPATERO, Javier. 2019. "Escritores en la gran pantalla: el biopic literario en el cine español contemporáneo». En Previtera, Roberta (ed.). El ojo que escribe (Estudios sobre las relaciones entre cine y literatura). Málaga: EDA, pp. $129-145$

WALSH, Andrew Samuel. 2004. Jaime Gil de Biedma y la tradición angloamericana. Granada: Universidad de Granada. 